\title{
CONDENSATION/ADSORPTION AND EVACUATION OF RESIDUAL GASES IN THE SRF SYSTEM FOR THE CESR LUMINOSITY UPGRADE*
}

\author{
$\underline{\text { R.L. Geng }}$ 立 $_{\text {, }}$ H. Padamsee, Laboratory of Nuclear Studies, Cornell Univ., Ithaca, NY14853
}

\begin{abstract}
Condensed/adsorbed gases can enhance field emission in superconducting cavities and deteriorate the input coupler performance in a superconducting RF system. It is therefore important to understand condensation/adsorption of residual gases in such a system. In this paper, we present some related results for the first two superconducting cavities installed in the CESR for luminosity upgrade. The total amount of adsorbed gases for different working periods are compared. Gas species are analyzed. A MonteCarlo computer code is used to simulate the gas condensation/adsorption profile along the waveguide. The warmup desorption curve is extracted, which might help us to understand the interaction between gas molecules and substrates. The pumping speed of the window pump-out box was evaluated by using the same code and was compared with the speed due to cryo-pumping. New designs of the pump-out box were explored to improve its pumping speed.
\end{abstract}

\section{INTRODUCTION}

Condensed/adsorbed gases can enhance field emission in superconducting cavities[1] and deteriorate the input coupler performance in a superconducting RF (SRF) system[2]. For SRF cavities installed in a routinely running accelerator, like B-cells for the CESR luminosity upgrade[3], the desorption and condensation/adsorption of residual gases are of great importance to the cavity performance, especially when high RF power and high beam current are involved. Possible gas sources in such a system include the ceramic window, beam line components nearby, and HOM absorbers. Gas molecules can be desorbed from surfaces of gas sources through different processes: heating of the ceramic window by RF power, heating of HOM absorbers by HOM power, bombarding of the waveguide and ceramic surfaces by multipacting electrons. The desorbed gases are finally condensed/adsorbed on the cold surfaces of the system, if not properly evacuated.

The implementation of SRF cavities (Fig. 1) for the CESR luminosity upgrade started from October 1997[4]. Till now, two cavities, referred to as E2 and E1, have been installed. During the commissioning period, it was found that the input coupler benefited a lot from room temperature warming-up cycles[5], during the course of which significant amount of gases evolved from the system. It was believed that gases condensed/adsorbed on the waveguide surface enhanced the secondary emission coefficient (SEC). As a result, more multipacting bands be-

\footnotetext{
* Work supported by the National Science Foundation.

$\dagger$ on leave from IHIP, Peking University, Beijing 100871, PRC.

‡Email: rg58@cornell.edu
}

came active[6] to cause RF trips. By warming up the cavity, most adsorbates were released, giving a "clean" surface with a lower SEC. Accordingly, the multipacting problem was alleviated.

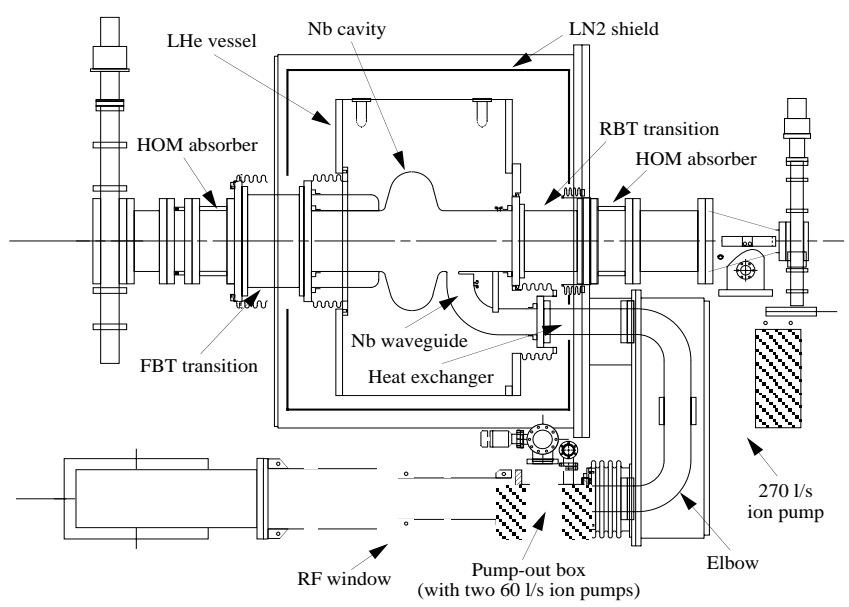

Figure 1: The SRF cavity for the CESR luminosity upgrade

It is always desirable to keep the gas load to the system as low as possible. This can be achieved by following ways. 1) Reducing gas content of gas sources, e. g. baking the window prior to the cavity cooling down. 2) Improving the pumping speed of the evacuating system.

\section{GAS EVOLUTION BY WARMING-UP}

During the cavity warming-up, ion pumps were used for evacuation with pressures monitored with cold cathode gauges installed near the pump ports. Fig 2 shows a typical pressure curve during a warming-up event. Total amount

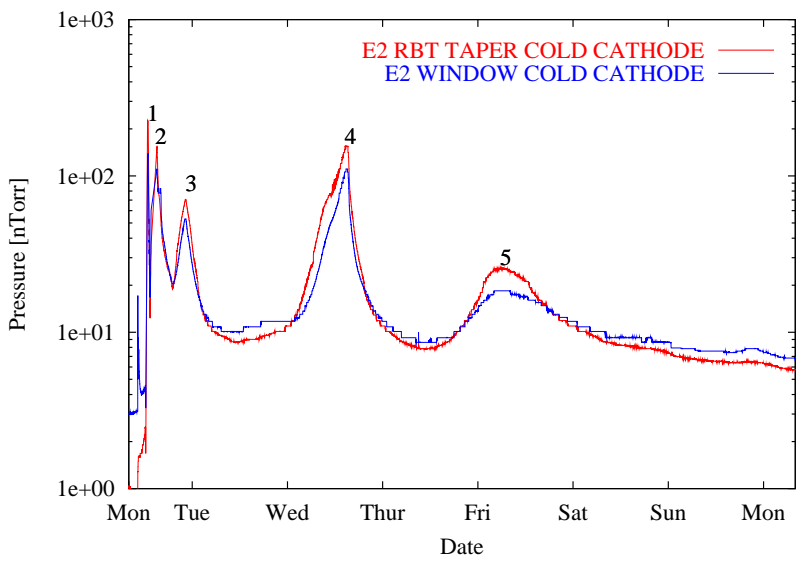

Figure 2: Pressures during the warming-up (E2, Jun.98) 
of evolved gases during warming-up was obtained by pressure integration. Table 1 shows results for the E2 and E1

Table 1: Gas evolution during the warming-up

\begin{tabular}{|c|c|c|c|}
\hline Cavity & $\begin{array}{c}\text { Warm Up } \\
\text { @ }\end{array}$ & $\begin{array}{c}\text { Gas evolution } \\
\text { [torr-Liter] }\end{array}$ & $\begin{array}{c}\text { Gas Layers } \\
{\left[\mathrm{H}_{2} \text { eq.] }\right.}\end{array}$ \\
\hline E2 & Feb. 98 & 14.68 & 7.03 \\
\hline E2 & Jun. 98 & 5.51 & 2.64 \\
\hline E2 & Oct. 98 & 9.25 & 4.43 \\
\hline E2 & Feb. 99 & 14.30 & 6.84 \\
\hline \hline E1 & Feb. 99 & 8.62 & 4.12 \\
\hline
\end{tabular}

Table 2: Integrated $P_{b}$ and $I_{b}$ between CESR down

\begin{tabular}{|c|c|c|c|c|}
\hline Cavity & $\begin{array}{c}\text { Warm } \\
\text { Up @ }\end{array}$ & $\begin{array}{c}\text { Total cold } \\
\text { time [day] }\end{array}$ & $\begin{array}{c}\int P_{b} d t \\
{[M W-h r]}\end{array}$ & $\begin{array}{c}\int I_{b} d t \\
{[A-h r]}\end{array}$ \\
\hline E2 & Feb. 98 & 120 & 138 & 440 \\
\hline E2 & Jun. 98 & 99 & 160 & 470 \\
\hline E2 & Oct. 98 & 90 & 184 & 490 \\
\hline E2 & Feb. 99 & 95 & 213 & 593 \\
\hline \hline E1 & Feb. 99 & 95 & 232 & 593 \\
\hline
\end{tabular}

cavities in different warming-up events. Note that the layer number of gases is given in that of an equivalent amount of $\mathrm{H}_{2}$ over an area of $3.3 \mathrm{~m}^{2}$, the total surface area of cold components, including the cavity, the cold He gas cooled heat exchanger (HEX), and the $\mathrm{LN}_{2}$ cooled RBT/FBT transitions and waveguide elbow.

Table 2 shows the total time that the cavity was cold, the integrated RF power delivered to the beam $\left(\mathrm{P}_{b}\right)$ and integrated CESR current $\left(I_{b}\right)$ over the period between the current warming-up and previous CESR down. The first warming-up of the E2 in Feb. 98 gave roughly 7 layers of equivalent $\mathrm{H}_{2}$ with only a $138 \mathrm{MW}-\mathrm{hr}$ integrated beam power delivered in the past four months. After the first warming-up, we were able to deliver more beam power. We found the more integrated beam power in the past four months, the more gas evolution during the succeeding warming-up. However, the gas evolution seems not directly correlated with the cold time, neither with the integrated current. The first warming-up of the E1 in Feb. 99 gave only 4 layers of equivalent $\mathrm{H}_{2}$ with a $232 \mathrm{MW}-\mathrm{hr}$ integrated beam power delivered in the past four months. In Comparison, the E1 has a much abated gas load and better performance upon the first warming-up. It was believed that the baking of the E1 window prior to the installation helped a lot in reducing the gas load.

\section{GAS SPECIES}

In Fig. 2, one can see several distinct pressure peaks. This is suggestive that different gas species are desorbed over the warming-up period. Fig. 3 shows the desorption curves, the cavity pressure as a function of the cavity temperature. All desorption curves, both for the E2 and E1, show pressure peaks at the same cavity temperatures. (Note that peaks between $100^{\circ} \mathrm{K}$ and $120^{\circ} \mathrm{K}$ are due to the turning off of the $\mathrm{LN}_{2}$ supply.)

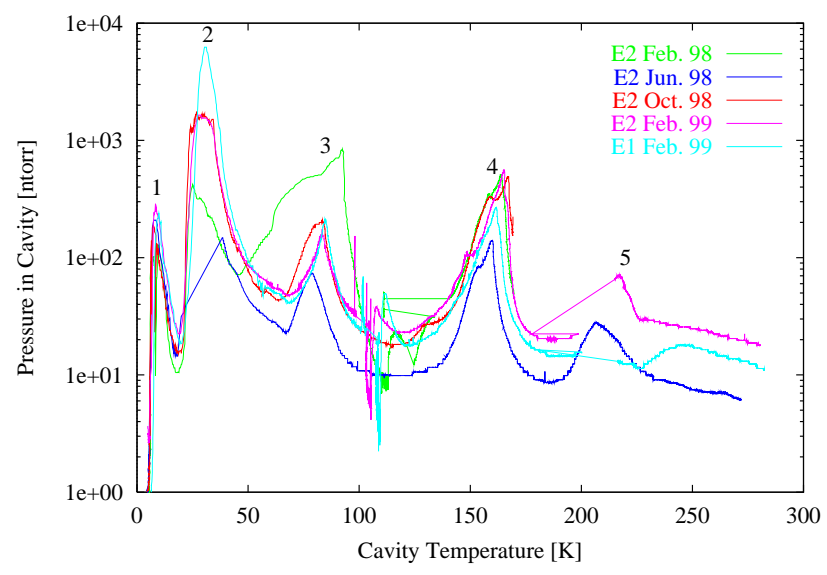

Figure 3: Warming-up desorption curves of cavities

RGA Spectrums, recorded during warming-up, indicates that residual gas species are mainly $\mathrm{H}_{2}, \mathrm{H}_{2} \mathrm{O}$, and $\mathrm{CO} / \mathrm{N}_{2}$, along with small amount of $\mathrm{CO}_{2}, \mathrm{O}_{2}, \mathrm{He}$ and $\mathrm{Ne}$. It is also indicated that different species prevail in different desorption peaks as shown in Table 3. For reference, temperatures of the cavity, the cold end of the HEX and the cold end of the elbow are also listed in the table. The exceptionally high amplitude of the third peak for the E2 warming-up in Feb. 98 suggests that excessive $\mathrm{CO}_{2}$ and $\mathrm{CO} / \mathrm{N}_{2}$ were adsorbed between the installation and the first warming-up of the $\mathrm{E} 2$ cavity.

Table 3: Prevailing gas species and nominal temperatures of the cavity, the HEX cold end, and the elbow cold end at the time of desorption peaks

\begin{tabular}{|c|c|c|c|c|}
\hline $\begin{array}{c}\text { Peak } \\
\#\end{array}$ & $\begin{array}{c}\text { Gas } \\
\text { species }\end{array}$ & $\begin{array}{c}\text { Cavity } \\
{\left[{ }^{\circ} \mathrm{K}\right]}\end{array}$ & $\begin{array}{c}\text { HEX } \\
{\left[{ }^{\circ} \mathrm{K}\right]}\end{array}$ & $\begin{array}{c}\text { Elbow } \\
{\left[{ }^{\circ} \mathrm{K}\right]}\end{array}$ \\
\hline 1 & $\mathrm{H}_{2}, \mathrm{He}$ & 9 & 22 & 85 \\
\hline 2 & $\mathrm{CO} / \mathrm{N}_{2}, \mathrm{H}_{2}, \mathrm{O}_{2}, \mathrm{Ne}$ & 27 & 35 & 92 \\
\hline 3 & $\mathrm{CO}_{2}, \mathrm{CO} / \mathrm{N}_{2}$ & 83 & 92 & 130 \\
\hline 4 & $\mathrm{H}_{2}, \mathrm{H}_{2} \mathrm{O}, \mathrm{CO} / \mathrm{N}_{2}$ & 163 & 165 & 190 \\
\hline 5 & $\mathrm{H}_{2}, \mathrm{H}_{2} \mathrm{O}$ & 230 & 220 & 240 \\
\hline
\end{tabular}

\section{WHERE DO GASES LODGE}

Among all possible gas sources, special attention was paid to the ceramic window, from which most gas load was suspected to come. If not properly evacuated, those gases would condense/adsorb on cold surfaces of the waveguide, or even enter the cell of the cavity through the tongue.

When the cavity is at $4.2^{\circ} \mathrm{K}$, measurements show that the elbow temperature ranges from $180{ }^{\circ} \mathrm{K}$ (warm end) to $80{ }^{\circ} \mathrm{K}$ (cold end) and the HEX temperature ranges from $45^{\circ} \mathrm{K}$ (warm end) to $10^{\circ} \mathrm{K}$ (cold end). Below $120^{\circ} \mathrm{K}$, $\mathrm{H}_{2} \mathrm{O}$ vapor pressure is many orders of magnitude lower 
than $1 \times 10^{-9}$ torr[7]. This means that virtually all the residual $\mathrm{H}_{2} \mathrm{O}$ would condense on the surface of the waveguide elbow, most likely that of the section from the middle to the cold end. By the same token, $\mathrm{CO}_{2}, \mathrm{CO} / \mathrm{N}_{2}$ and $\mathrm{O}_{2}$ would condense on the surface of the HEX.

A Monte-Carlo simulation code, MOLFLOW[8], was used to estimate the condensation profile of $\mathrm{CO}_{2}, \mathrm{CO} / \mathrm{N}_{2}$ and $\mathrm{O}_{2}$ along the HEX. A unity sticking coefficient $(s)$, regardless the condensation thickness[7], was used for these species. The results suggested that $90 \%$ of these gases would condense on the HEX surface with an exponential distribution. Only $10 \%$ of them might enter the $\mathrm{Nb}$ waveguide of the cavity.

The residual $\mathrm{H}_{2}$ is the hardest to condense $\left(\mathrm{H}_{2}\right.$ vapor pressure is higher than $1 \times 10^{-6}$ torr even at $4.2^{\circ} \mathrm{K}$ ). However, there are possibilities for the $\mathrm{H}_{2}$ to be adsorbed by a $4.2{ }^{\circ} \mathrm{K} \mathrm{Nb}[9]$ and a $10{ }^{\circ} \mathrm{K}$ copper plated stainless steel[10][11]. Fig. 4 shows the simulation result on the

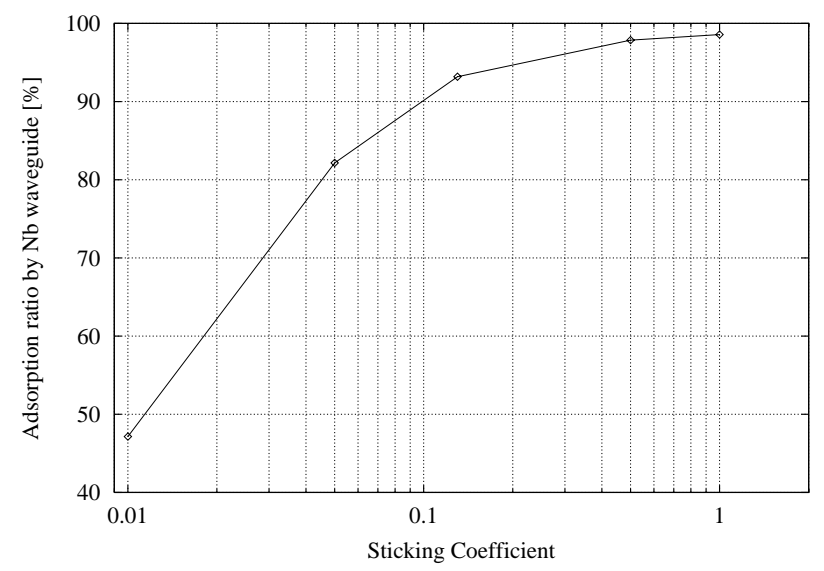

Figure 4: Ratio of the $\mathrm{H}_{2}$ adsorbed by the $\mathrm{Nb}$ waveguide to that enters the cell of the cavity as a function of $s$

ratio of the $\mathrm{H}_{2}$ adsorbed on the $\mathrm{Nb}$ waveguide to that enters the cell of the cavity. Experimental data[12] show that the $s$ of $\mathrm{H}_{2}$ on a clean $\mathrm{Nb}$ surface at $77^{\circ} \mathrm{K}$ is 0.2 and decreases quickly with $\mathrm{H}_{2}$ uptake, reaching 0.05 after 3 mono-layers of adsorption. This suggests that more than $80 \%$ of the initial $\mathrm{H}_{2}$ gas load from the ceramic would adsorb on the surface of the $\mathrm{Nb}$ waveguide. The other $20 \%$ might be able to enter the cell of the cavity through the coupler tongue. With more $\mathrm{H}_{2}$ gas load, there are more chances for the $\mathrm{H}_{2}$ to enter the cell of the cavity.

According to the previous analysis, it is quite likely that the HEX and the top half of the elbow are well coated with condensable gases, like $\mathrm{CO}_{2}, \mathrm{CO} / \mathrm{N}_{2}$ and $\mathrm{H}_{2} \mathrm{O}$. Those precoated condensates usually provide effective cryo-sorption of the $\mathrm{H}_{2}$ [7], which means that the chance of the $\mathrm{H}_{2}$ entering the cell could be much lower than $20 \%$. In Table 3, it is shown that the $\mathrm{H}_{2}$ presents nearly in all the desorption peaks. This is a direct indication that part of the $\mathrm{H}_{2}$ is adsorbed on surfaces of the HEX and the elbow in mixing with condensable gases.

\section{EVACUATING RESIDUAL GASES}

A powerful evacuation system is always desirable to compete effectively with the cryo-pumping due to cold surfaces.

The estimated cryo-pumping speed is $600 \mathrm{l} / \mathrm{s}$ with respect to the gas load from the ceramic. MOLFLOW simulations show that the E2 pump-out box gives only a $30 \mathrm{l} / \mathrm{s}$ net pumping speed. Modifications on the E1 pump-out box were pursued. The net pumping speed was improved to 60 l/s.

To compete with the cryo-pumping, further improvement on the pump-out box is favorable. A suggested configuration, consisting of 250 shower drain holes, $120 \mathrm{~mm}$ ID elbows and 500 1/s pumps, will give a 320 1/s net pumping speed, which is hopefully able to compete with the $6001 / \mathrm{s}$ cryo-pumping.

\section{CONCLUSIONS}

Gas evolution during warming-up of the CESR SRF cavities was evaluated. A few equivalent mono-layers of $\mathrm{H}_{2}$ were adsorbed on cold surfaces, even after several warming-ups. There seems to be a correlation between the integrated beam power and the gas evolution during the succeeding warming-up. Residual gas species were found mainly $\mathrm{H}_{2}, \mathrm{H}_{2} \mathrm{O}$, and $\mathrm{CO} / \mathrm{N}_{2}$. They condensed/adsorbed selectively on surfaces of different sections. The initial $\mathrm{H}_{2}$ was most likely adsorbed on the $\mathrm{Nb}$ waveguide surface. With heavier $\mathrm{H}_{2}$ gas load, $\mathrm{H}_{2}$ molecules could enter the cell of the cavity and adsorb on the cell surface. The current pumping speed of the pump-out box is much lower than that due to cryo-pumping. Further modifications on the pump-out box is necessary to compete with the cryopumping.

\section{REFERENCES}

[1] Q.S. Shu et al., IEEE Trans. Magn. 25, 1868(1989).

[2] E. Haebel et al., Proc. 7th workshop on RF superconductivity (Gif sur Yvette, France,1995), p.707.

[3] H. Padamsee et. al., Proc. PAC91, (San Francisco, 1991), p. 786.

[4] S. Belomestnykh, these proceedings.

[5] H. Padamsee, Proc. EPAC98 (Stockholm, Sweden, 1998).

[6] R.L. Geng and H.S. Padamsee, these proceedings.

[7] R.A. Haefer, Cryopumping: theory and practice, Clarendon Press, Oxford, 1989.

[8] R. Kersevan, MOLFLOW, a 3-D Monte-Carlo program, available from the author, now at ESRF, Grenoble, France; a $\mathrm{C}$ version has been developed at Laboratory of Nuclear Studies, Cornell University, available from N. Mistry.

[9] M.G. Rao, P. Kneisel and J. Susta, Cryogenics, 34, 377(1994).

[10] S. Anderson et. al., Phys. Rev., B40(12), 8146(1989).

[11] E. Wallen, J. Vac. Sci. Technol., A14(5),2916(1996).

[12] S.M. Ko and L.D. Schmidt, Surf. Sci., 42(2), 508(1974). 